\title{
Genetics of the patella
}

\author{
Mark E. Samuels ${ }^{1,2} \cdot$ Philippe M. Campeau $\mathbb{C}^{3}$
}

Received: 15 December 2017 / Revised: 22 November 2018 / Accepted: 27 November 2018 / Published online: 21 January 2019

(c) European Society of Human Genetics 2019

\begin{abstract}
We review genetic diseases with identified molecular bases that include abnormal, reduced (hypoplasia), or absent (aplasia) patellae as a significant aspect of the phenotype. The known causal genes can be broadly organized according to three major developmental and cellular processes, although some genes may act in more than one of these: limb specification and pattern formation; DNA replication and chromatin structure; bone development and differentiation. There are also several genes whose phenotypes in mice indicate relevance to patellar development, for which human equivalent syndromes have not been reported. Developmental studies in mouse and chick embryos, as well as patellar involvement in human diseases with decreased mobility, document the additional importance of local environmental factors in patellar ontogenesis. Patellar anomalies found in humans can be an important clue to a clinical genetic diagnosis, and a better knowledge of the genetics of patellar anomalies will improve our understanding of limb development.
\end{abstract}

\section{Development of the patella}

The patella is a large sesamoid bone present in the human knee. Sesamoid bones as a group are defined by their origin within cartilaginous tissue. The term sesamoid is sometimes used less specifically to include any of a variety of accessory ossicles occurring near joints [1]. In humans, most sesamoid bones are small, mostly found in the hands and feet, and are frequently variable in occurrence (i.e., are not present in all individuals). The patella is by far the largest human sesamoid bone, is invariable and is the only one routinely included in the total bone count (although the fabella is sometimes included). The patella is only one among several ossicles that occur in the knee joint in humans and other animals (see Fig. 1 of Samuels et al. [2])

Supplementary information The online version of this article (https:// doi.org/10.1038/s41431-018-0329-6) contains supplementary material, which is available to authorized users.

Mark E. Samuels

mark.e.samuels@umontreal.ca

1 Département de médicine, Université de Montréal, Montreal, Canada

2 Centre de Recherche du CHU Ste-Justine, Montreal, Canada

3 Department of Pediatrics, Centre de Recherche du CHU SteJustine, Montreal, Canada
Regarding nomenclature, the field unfortunately lacks consensus on the precise meaning of the term "patella". Many articles use the term to include pre-ossified cartilaginous structures, or even pre-chondrocyte primordial cells, in the developing knee joint. In others, the term is used for the final ossified skeletal element. There is some discrepancy between the evolutionary literature, in which the term usually implies a bone as in most cases only fossilized specimens are available, and the developmental literature, in which pre-ossified structures are readily observed in model organisms (or humans). In this review, we employ the term broadly to include both the ossified element and definitive non-ossified precursors as appropriate.

Developmentally, the patella is not yet ossified at birth in humans and in other organisms that have been studied (mouse, rabbit, chick). In the human embryo, a patellar anlage has been observed as early as stage 19 fetuses (7 weeks, $16-21 \mathrm{~mm}$ ), and in most or all stage 20 fetuses (7 weeks, $18-23 \mathrm{~mm}$ ) [3]. At this point, it has been described as a cellular condensate or blastema, with no obvious cell subtype or identified biomarkers. Shortly thereafter the patellar anlage becomes chondrified as a "hyaline cartilage mass" [4], at approximately the same time as cavitation of the knee inter-zone begins [5]. In humans, ossification typically begins at 5-6 years of age (sometimes earlier) at several small internal foci, which grow and eventually merge, with completion of ossification during adolescence. There is a general (though not universal) 
Fig. 1 Basic anatomy of the human knee joint seen angled from the rear. Proximal/distal and dorsal/ventral pattern formation axes are with respect to the generalized Tetrapoda hind limb. Illustration: Manuela Bertoni

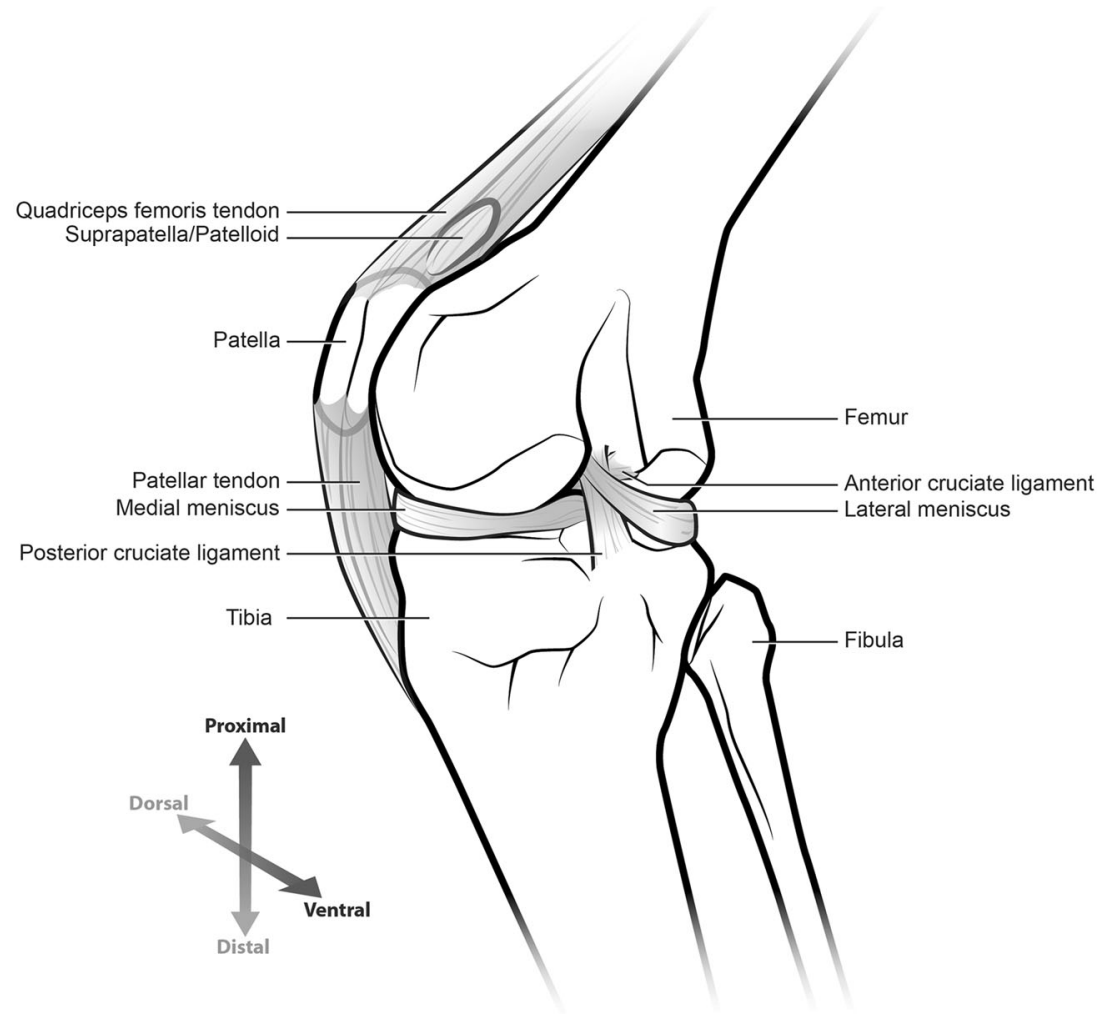

consensus that the patella develops within the quadriceps femoris tendon (Fig. 1) and hence is a true sesamoid.

The delayed ossification of the patella introduces an aspect of potential uncertainty in interpreting the genetics of this structure. Patellar hypoplasia or aplasia is typically defined through radiographic imaging, sometimes with manual inspection, but these are ambiguous or infeasible in very young children and infants. In most examined cases, the definition is with respect to the final ossified skeletal element, thus cases ascertained very young cannot be assessed reliably for patellar status. In many cases, it is also unclear whether there is any patellar primordium or cartilaginous material, although some case reports do comment on whether any palpable material is present in the knee joint at the appropriate position. Therefore it is rarely possible to distinguish a failure of patellar development per se from a later stage partial or complete failure of ossification. Patellar biopsies are not typically performed, therefore the presence of cartilaginous patellar material usually remains uncertain. This makes interpretation of patellar determination vis-à-vis differentiation challenging.

\section{Evolution of the patella}

The patella as a skeletal element is far from universal among Tetrapoda (Supplemental Figure S1). It is definitively absent from early tetrapods, including primitive reptiles, dinosaurs, and pre-mammalian ancestors such as the Cynodontia. Among modern groups a true ossified patella is found in most birds (Aves, descendants of dinosaurs), many or most lizards (Squamata), and many mammals [6, 7]. It is absent in other reptiles including Crocodilia and Testudinae (turtles), thus appears to have evolved independently at least three times in the largest extant tetrapod clades (birds, lizards, mammals). Even within mammals, patellar occurrence is complex [2]. It is found almost universally in placental mammals (Eutheria), but is absent in most marsupials (Metatheria). It is found in a small number of species in several marsupial sub-clades, whose members' lifestyles are not obviously similar to each other. Even more unexpectedly, a large patella occurs in the extant egg-laying mammals (Monotremata) such as the platypus, that diverged much earlier than the placental-marsupial divergence. A patella is also found among several extinct mammalian groups, in side branches unrelated to any of the three extant mammalian clades (Eutheria, Metatheria, Monotremata). Thus, the patella has a complex evolutionary history, with likely multiple introductions and possibly also losses in diverse groups. Similar histories of convergent traits have now been described for a variety of anatomical features such as the cecal appendix [8]. The study of patellar genetic syndromes in humans and other model systems thus has the potential to inform evolutionary studies. 


\section{Genetics of the patella}

Here we discuss human genetic disorders with identified molecular bases that include abnormal, reduced, or absent bony patellae (hypoplasia or aplasia) as a significant aspect of the phenotype (previously reviewed in refs. [9-11]). The proportion of cases with patellar involvement is variable among these disorders; such involvement may be typical (most or all reported cases), or atypical (one or only some cases). For some syndromes, the number of characterized cases is too small to know the fraction with patellar involvement. To limit the scope of this discussion, we have excluded syndromes in which the patella is affected at the same time as many or most other skeletal structures, thus with little or no specificity. Syndromes with a well-defined patellar component but no identified gene are discussed in the Supplement. Developmental studies in mouse or chick embryos document the additional importance of local environmental factors in patellar development $[12,13]$.

Perhaps unexpectedly, many or most of the causal genes for these syndromes can be broadly organized according to only three major developmental processes, although some genes may act in more than one of these: limb specification and joint pattern formation, DNA replication and chromatin, or bone development and regulation (Fig. 2, with four temporally defined stages not uniquely correlated with the three processes). It should be kept in mind that some of the implicated genes discussed here may play additional, as yet undefined physiological roles, therefore, the inference that the specific developmental processes proposed here are in fact the ones disturbed by functional variants in the particular genes remains to be proven in many cases.

In many of the human syndromes, the causal variants are either heterozygous (transmitted from an affected parent or arising de novo presumably in the parental germ line), or if homozygous or compound heterozygous then at least one allele is a simple substitution. For many of the associated genes, complete loss of function of both alleles may be either lethal or else yield a much more severe phenotype. Thus, it is not implied that the syndromes described here represent the definitive phenotype for the genes involved. Rather, they implicate the genes in the processes of patellar determination and/or differentiation.

\section{Disorders likely of pattern formation and joint specification}

(Table 1) Interpretation of pattern formation syndromes with respect to the patella is aided by a more general understanding of its embryological determinants. The patella arises in the knee joint of the hind limb, thus genes involved in the specification of these positions are anticipated to play a role in patellar ontogeny. In embryological terms, specification of hind versus forelimbs occurs along

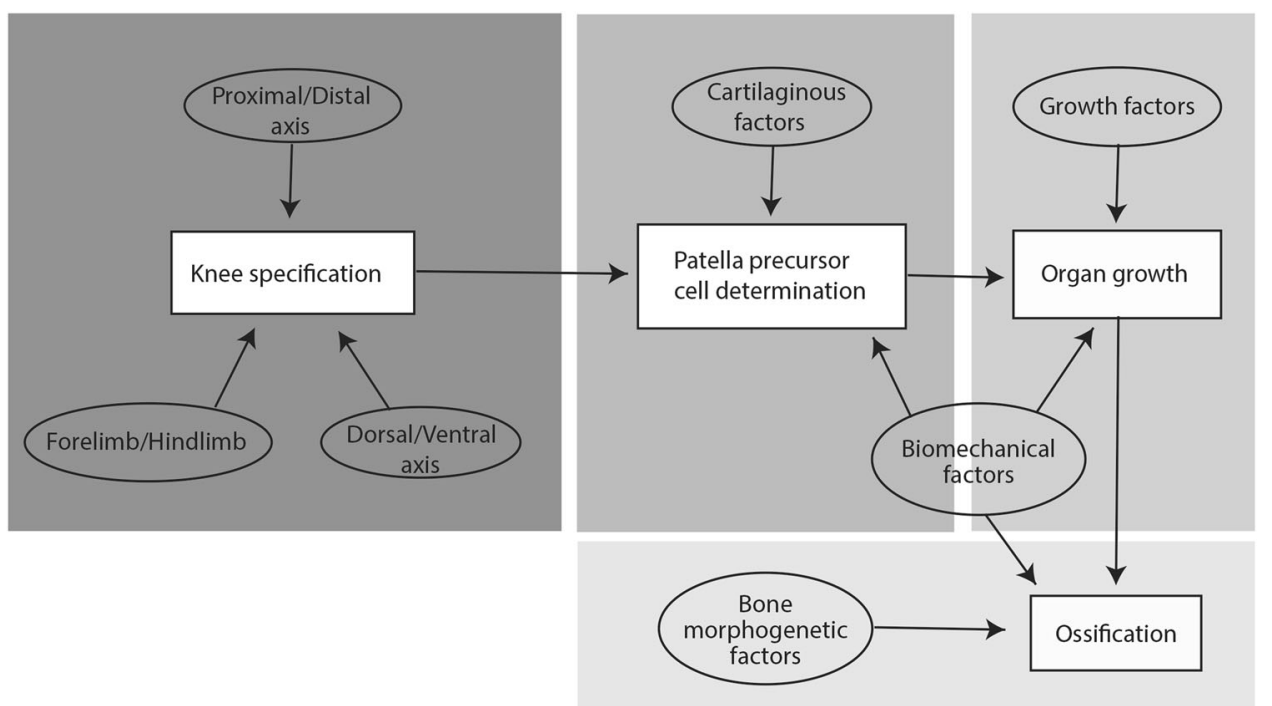

Fig. 2 Temporal development of the patella. First, the anatomical location of the patellar anlage is determined, with respect to multiple body axes: rostral/caudal, via forelimb/hind limb specification; proximal/distal, positioning the anlage at the junction of the stylopod (future femur) and zeugopod (future tibia/fibula); and dorsal/ventral, positioning the anlage on the correct side of the future knee joint. Second, the cells of the patellar anlage are determined and begin to differentiate into cartilaginous-like tissue. Third, the patellar anlage grows to the appropriate size and shape, which varies significantly among different mammalian species [2]. Fourth and finally, beginning $\sim 5$ years after birth and taking as much as a decade for completion, multiple ossification centers form within the cartilaginous pre-patella and merge to form the final sesamoid patella. Several of these events are likely to require non-genetic local environmental (biomechanical) factors. It remains uncertain which of these processes require the patellar syndrome genes involved in DNA replication or chromatin regulation, although replication genes are likely to play a role during the phase of patellar organ growth 
Table 1 Disorders likely of pattern formation and joint specification

\begin{tabular}{|c|c|c|c|c|c|}
\hline Syndrome [MIM] & $\begin{array}{l}\text { Patellar } \\
\text { involvement }\end{array}$ & Gene [MIM] & Mode of transmission & Molecular function & $\begin{array}{l}\text { Developmental } \\
\text { Process }\end{array}$ \\
\hline $\begin{array}{l}\text { Nail-patella } \\
{[161200]}\end{array}$ & Typical & $\begin{array}{l}L M X 1 B \\
{[602575]}\end{array}$ & $\begin{array}{l}\text { Dominant, probable } \\
\text { haploinsufficiency }\end{array}$ & Transcription factor & Limb patterning \\
\hline $\begin{array}{l}\text { Ischiocoxopodopatellar (small } \\
\text { patella) }\end{array}$ & Typical & $T B X 4$ & $\begin{array}{l}\text { Dominant, possible } \\
\text { haploinsufficiency }\end{array}$ & Transcription factor & Limb patterning \\
\hline$[147891]$ & & [601719] & & & \\
\hline $\begin{array}{l}\text { Clubfoot with long bone } \\
\text { deficiencies }\end{array}$ & Atypical & PITX1 & $\begin{array}{l}\text { Dominant, possible } \\
\text { haploinsufficiency }\end{array}$ & Transcription factor & Limb patterning \\
\hline [119800] & & [602149] & & & \\
\hline $\begin{array}{l}\text { Fuhrmann } \\
{[228930]}\end{array}$ & Atypical & $\begin{array}{l}\text { WNT7A } \\
{[601570]}\end{array}$ & $\begin{array}{l}\text { Recessive, possible } \\
\text { hypomorphic }\end{array}$ & Cell-cell signaling & Limb patterning \\
\hline Laurin-Sandrow [135750] & Atypical & $\begin{array}{l}\text { LMBR1 } \\
{[605522]}\end{array}$ & $\begin{array}{l}\text { Dominant, probable gain } \\
\text { of function }\end{array}$ & Putative receptor & Limb patterning \\
\hline $\begin{array}{l}\text { Acromelic frontonasal dysostosis } \\
\text { [603671] }\end{array}$ & Atypical & $\begin{array}{l}\text { ZSWIM6 } \\
{[615951]}\end{array}$ & $\begin{array}{l}\text { Dominant, possible gain of } \\
\text { function }\end{array}$ & $\begin{array}{l}\text { Zinc finger with } \\
\text { SWIM domain }\end{array}$ & $\begin{array}{l}\text { Possibly limb } \\
\text { patterning }\end{array}$ \\
\hline
\end{tabular}

the cranial-caudal axis of the body. Along the length of each limb, the structure nearest the spine (proximal) is generally referred to as the stylopod (including the femur in the legs and humerus in the arms); the next distal structure is the zeugopod (tibia/fibula in the legs, radius/ulna in the arms); final the most distal structure is the autopod (feet and hands). Thus, the knee is the joint defined at the intersection of the hind limb stylopod and zeugopod. Finally, the patella is a dorsal structure (Fig. 1). This is not intuitively obvious in humans as the legs rotate in the hip joint with respect to the rest of the body during development, as compared with the primitive tetrapod body plan. In humans, this is more evident for the elbow, which more naturally faces dorsally when the arm hangs in a neutral position. Thus, genes specifying the proximal/distal axis, the stylopod/zeugopod joint along this axis, and the dorsal/ventral axis are expected to play roles in patellar ontogeny. The forelimb ulnar olecranon, a bony extension of the dorsal main shaft of the ulna, is in a developmental sense the elbow equivalent to the patella in terms of pattern forming elements, although it arises through a different process and is not a sesamoid.

Nail-patella syndrome (NPS, MIM[161200]) is a rare dominant human genetic disorder with multiple skeletal abnormalities, including but not limited to nail dysplasia with patellar aplasia or hypoplasia [14]. The patella can also be irregularly shaped, mis-localized or prone to dislocations (in part because of associated muscle anomalies). The elbow is also affected, typically with reduction of the radial head and/or capitella, leading to dislocation of the radius [15]. NPS is caused by haplo-insufficient variants in the LIM-homeodomain transcription factor LMXIB (MIM [602575]) [16]. Homozygous mice lacking the gene are also missing dorsal limb structures, indicating that $L M X 1 B$ has a key role in dorsal-ventral patterning at least in placental mammals. The missing patella is thus probably secondary to a more fundamental failure of dorsal determination in the hind limb. A syndrome named Nail-patella-like renal disease (MIM[256020]) is reported in a single case [17], however the article abstract states that there was no bone or nail phenotype in the patient, only renal involvement, thus this is apparently not actually a patellar disorder.

Ischiocoxopodopatellar syndrome (ICPPS, MIM [147891], previously called small patella syndrome, SPS) is a rare dominant disorder primarily affecting pelvic and hind limb bone development, including hypo- or aplastic patellae $[18,19]$. General musculature and nails of the fingers and toes are normal. ICPPS is caused by variants in transcription factor TBX4 (MIM[601719]) [20]. As with $L M X 1 B$, the missing patella in this syndrome appears secondary to a more profound failure of determination, in this case of the hind (lower) limb versus the fore (upper) limb. Extensive studies of Tbx4 function in mice, birds, and fish confirm its role in hind limb specification, although the exact timing and role of its function remains somewhat unclear [21, 22]. Tbx4 plays additional roles in development as knockout mice have much more severe phenotypes than simple limb abnormalities [23]. Intriguingly, $T b x 4$ ectopically expressed in the forelimb region of $T b x 5$ knockout mice (which lack forelimbs) was able to partially rescue the phenotype, suggesting that $T b x 4$, while necessary, is not sufficient to specify hind limbs, at least in mice [24].

The primary phenotype of functional variants in the transcription factor PITXI (MIM[602149]) is congenital clubfeet (CCF, MIM[119800]) often with other limb anomalies such as polydactyly, but one variant is reported to also cause patellar hypoplasia [25]. Other structural variants in the gene, possibly in regulatory elements, cause a more generalized homeotic-like transformation of the 
forelimbs (arms) toward hind limbs (legs), with reduction or absence of the olecranon, and presence of a novel ossified structure on the humerus reminiscent of a (fused) patella, as well as wrist anomalies [26]. Pitxl homozygous knockout mice have reduced hind limbs with lack of an obvious ossified patella [27, 28], whereas ectopic expression of Pitxl in forelimbs drives hind limb-like pattern formation yet without an actual ossified patella, both in mice [29] and in chicks [30]. As with TBX4, the action of PITX1 in patellar development probably relates to its role in hind/ forelimb determination.

Fuhrmann syndrome (FS, MIM[228930]) is a disorder of limb and joint development, of varying severity with limb bowing, hypo- or aplastic femur, ulna or fibula, digital anomalies, hypo- or aplastic patellae, reduced or absent nails, sometimes with short stature and amenorrhea [31, 32]. It can be caused by variants in the intercellular signaling factor $W N T 7 A$, for which a role in limb pattern formation has been demonstrated in model organisms [33, 34]. Different variants in WNT7A also cause the more phenotypically severe Al-Awadi-Raas-Rothschild limb/ pelvis/uterus-hypoplasia-aplasia syndrome (AARRS, MIM [276820], also known as Schinzel phocomelia). There is at least one case report consistent with an FS diagnosis for which variants in $W N T 7 A$-affecting function were not found, thus there may be genetic heterogeneity for this disorder. That case was too young to assess patellar status.

Laurin-Sandrow syndrome (LSS, [MIM 135750]) is one of several genetic disorders associated with variants in gene LMBR1 [MIM 605522]. LSS includes multiple skeletal abnormalities typically of the limbs, including mirror image polydactyly. At least one reported case involved patellar aplasia [35]. Although LMBR1 is the gene associated with LSS, the specific causal variants involve duplications of an intronic enhance element mediating sonic hedgehog regulation in limbs [36]. In contrast to LSS, a large truncating deletion in LMBRI causes acheiropodia, absence of both hands and feet with arms and legs ending in stumps [37]. Similarly in mice dominant versus recessive, gain versus loss-of-function phenotypes result from different classes of variants in mice. These results suggest that the LSS and related less severe phenotypes of $L M B R 1$ in humans also result from gain of function, possibly through ectopic expression of the gene. Despite these extensive genetic studies, little is known regarding the biochemical or cellular function of the LMBR1 protein itself. LMBR1 contains multiple putative transmembrane domains, and is proposed to be a receptor or other cell membrane molecule which in flies can potentiate bone morphogenetic protein signaling [38].

Acromelic frontonasal dysostosis [MIM 603671] is a developmental syndrome with severe craniofacial dysmorphologies and variable involvement of the central nervous system together with limb abnormalities. Patellar hypoplasia is observed in some cases. All molecularly characterized cases carry a single recurrent missense variant in the gene ZSWIM6, encoding a SWIM-type zinc finger domain whose specific biochemical function remains to be described [39]. Where parents of the probands were available, they lacked the variant, suggestive of a de novo variant. The variant is proposed to disrupt normal hedgehog signaling, suggestive of a defect in pattern formation. It seems likely that the phenotype in humans is a gain of function, hence the role of ZSWIM6 in normal patellar development is uncertain.

\section{HOX genes in mice}

A number of mouse $H O X$ gene mutants have been engineered, which have effects on hind limb development. There are four vertebrate $H O X$ gene clusters on different chromosomes (named HOXA, HOXB, HOXC, HOXD), and at each locus genes are named in proximal-distal order, such as $H O X A 1, H O X A 2, \ldots, H O X B 1, H O X B 2, \ldots$, etc. There are up to 13 individual $H O X$ genes per cluster, but individual and different genes have been evolutionarily lost in each cluster in various vertebrate lineages. $H O X$ genes play roles in multiple developmental processes including limb formation [40]. Of the 39 human HOX genes, syndromes have been identified resulting from variants in nine to date: HOXA1, A2, A11, A13, B1, C13, D4, D10, and D13. The phenotypes of these syndromes are diverse, with some involving limb abnormalities, however patellar features have not been reported. Genetics of the Hox genes has been intensively studied in mice through targeted mutagenesis. Of particular interest is the triple homozygous knockout of all three mouse Hox11 genes, Hoxaaccdd-11 (Hoxb11 is permanently inactivated in the mouse genome) [41]. Among other features, these mice as embryos have an atypical hind limb knee skeletal morphology described as tripartite, although the patella appears to be present and normal. More surprisingly, in these mice an ectopic ulnar patella develops in the forelimb in place of the olecranon. Mice lacking Hoxd-10 are viable, and also have hind limb defects, with a position shift of the patella proximally along the knee joint, and occurrence of another ectopic sesamoid bone proximal to the patella [42]. Mice deleted for various combinations of Hoxa-10, Hoxa-11, Hoxd-9, or Hoxd-10 also show anomalous patellar morphologies and/or multiple knee sesamoids [43]. To date no human genetic syndromes are reported to involve any of the HOX9 genes, whereas a heterozygous variant of $H O X D 10$ causes abnormality of the ankle [44], and a heterozygous variant of HOXA11 causes amegakaryocytic thrombocytopenia together with 
Table 2 Disorders likely of DNA replication and/or chromatin

\begin{tabular}{|c|c|c|c|c|c|}
\hline Syndrome [MIM] & $\begin{array}{l}\text { Patellar } \\
\text { involvement }\end{array}$ & Gene [MIM] & $\begin{array}{l}\text { Mode of } \\
\text { transmission }\end{array}$ & $\begin{array}{l}\text { Molecular } \\
\text { function }\end{array}$ & $\begin{array}{l}\text { Developmental } \\
\text { Process }\end{array}$ \\
\hline $\begin{array}{l}\text { Meier-Gorlin 1-7 } \\
\text { [224690, 613800, } \\
613803,613804, \\
613805,616835, \\
617063]\end{array}$ & Typical & $\begin{array}{l}\text { ORC1 [601902], ORC2 [601182], ORC4 } \\
\text { [603056], ORC6 [607213], CDT1 [605525], } \\
\text { CDC6 [602627], GMNN [602842], CDC45 } \\
\text { [603465] }\end{array}$ & $\begin{array}{l}\text { Recessive, partial } \\
\text { loss of function }\end{array}$ & $\begin{array}{l}\text { Origin } \\
\text { recognition } \\
\text { binding }\end{array}$ & $\begin{array}{l}\text { DNA } \\
\text { replication, cell } \\
\text { division }\end{array}$ \\
\hline $\begin{array}{l}\text { RAPADILINO } \\
{[266280]}\end{array}$ & Typical & $\begin{array}{l}\text { RECQL4 } \\
{[603780]}\end{array}$ & $\begin{array}{l}\text { Recessive, loss of } \\
\text { function }\end{array}$ & DNA helicase & $\begin{array}{l}\text { DNA } \\
\text { replication, cell } \\
\text { division }\end{array}$ \\
\hline $\begin{array}{l}\text { Genitopatellar } \\
{[606170]}\end{array}$ & Typical & $\begin{array}{l}\text { KAT6B } \\
{[605880]}\end{array}$ & $\begin{array}{l}\text { Dominant, } \\
\text { probable } \\
\text { haploinsufficiency }\end{array}$ & $\begin{array}{l}\text { Histone } \\
\text { acetyltransferase }\end{array}$ & Chromatin \\
\hline $\begin{array}{l}\text { Proteus } \\
{[176920]}\end{array}$ & Typical & $\begin{array}{l}A K T 1 \\
{[164730]}\end{array}$ & $\begin{array}{l}\text { Dominant, gain of } \\
\text { function }\end{array}$ & $\begin{array}{l}\text { Phosphoinositide } \\
\text { 3-kinase }\end{array}$ & Cell growth \\
\hline $\begin{array}{l}\text { Roberts } \\
\text { [268300] }\end{array}$ & Atypical & $\begin{array}{l}\text { ESCO2 } \\
{[609353]}\end{array}$ & $\begin{array}{l}\text { Recessive, loss of } \\
\text { function }\end{array}$ & $\begin{array}{l}\text { Sister chromatid } \\
\text { cohesion } \\
\text { acetyltransferase }\end{array}$ & $\begin{array}{l}\text { DNA } \\
\text { replication, cell } \\
\text { division }\end{array}$ \\
\hline Seckel [210600] & Atypical & $A T R$ [601215] & $\begin{array}{l}\text { Recessive, } \\
\text { probable loss of } \\
\text { function }\end{array}$ & Kinase & $\begin{array}{l}\text { DNA } \\
\text { replication, } \\
\text { repair }\end{array}$ \\
\hline
\end{tabular}

radioulnar synostosis, i.e., abnormality of upper limb development [45].

\section{Disorders likely of DNA replication and/or chromatin}

(Table 2) Variants in genes implicated in limb specification and patterning are reasonably obvious in terms of their potential role in patellar dysostosis. In contrast, there is a group of genetic syndromes whose causal genes play a much more general cellular role, and whose involvement in patellar development is less readily explained. Although the syndromes are phenotypically pleiotropic and diverse, and the biochemical functions of the causal genes differ, they are united by their involvement with chromatin structure and/or DNA replication.

Meier-Gorlin Syndrome (originally MGS, now MGORS, also called ear-patella-short stature syndrome, [MIM 224690]) is a recessive developmental disorder including hypo- or aplastic patellae with other pleiotropic features including short stature and small ears [46]. The absent or reduced patellae in MGORS have significant impact on locomotor function in many of the affected patients, who may require surgery, leg braces or wheelchairs. The molecular basis of MGORS has now been clarified, with causal variants in multiple genes encoding components of the DNA replication machinery: ORC1, ORC4, ORC6, CDT1, CDC6, GMNN, MCM5, and CDC45 have been reported to date [47-52]. The $O R C$-encoded proteins function as a complex that binds to eukaryotic DNA origins as the first step in replication, with subsequent binding of CDT1 (after its release from GMNN), CDC6 and ultimately the MCM complex [53, 54]. Only one of these genes appears to be mutated in any individual patient; there are no examples of di-genic inheritance (so far). The aspect of small total body size (stature) is hypothesized to result from reduced total cell number, itself caused by increased time required for more widely spaced replication forks to fuse, thereby slowing overall mitosis. It is unclear why replication defects would lead to small ears and patellar aplasia; conceivably cells in these tissues have a special requirement for rapid replication or cell division as part of the normal developmental program. However, other syndromes of primordial dwarfism, including some variants in $O R C 1$, do not include a patellar phenotype [55], thus there may be another, unidentified role for the replication machinery in patellar development, perhaps to regulate specific gene expression via chromatin structure. $O R C 1$ is also implicated in cilia function, although a potential involvement of cilia in the MGORS phenotype is speculative.

Radial patellar hypoplasia, which includes cleft or arched palate, diarrhea, and dislocated joints, little size and limb malformation, nose slender and normal intelligence (RAPADILINO, [MIM 266280]) is a recessive developmental disorder with multiple limb deformations including patellar hypo- or aplasia [56]. The causal gene is a DNA helicase, RECQL4, in which variants can also cause the phenotypically overlapping syndromes of RothmundThompson (RTS, MIM[268400]) and Baller-Gerrold (BGS, [MIM 218600]) [57]. RECQL4 patients generally retain some gene function, and some mouse gene deletions 
are severely disabled or die as embryos or shortly after birth, suggesting a complete gene deletion might be lethal in humans [58]. The RECQL4 protein has been documented as a component of the MCM complex of the DNA replication machinery [59], but it may play additional roles in DNA repair and in mitochondria.

Genitopatellar syndrome (GPS, [MIM 606170]) includes patellar aplasia as a prominent aspect of the phenotype, in addition to urogenital abnormalities, intellectual deficit, and facial dysmorphology $[60,61]$. GPS is caused by variants in the gene $K A T 6 B$ encoding a histone acetyltransferase (formerly called MYST4 or MORF) [62, 63]. GPS patients are heterozygous for variants which probably arise de novo in parental germ lines. Heterozygous de novo truncating variants in $K A T 6 B$ can also cause the pleiotropic Say-BarberBiesecker Variant of Ohdo Syndrome (SBBYSS, MIM [603736]). SBBYSS is generally different than GPS, although hypoplastic patellae are an aspect of both syndromes. A chromosomal translocation that inactivated one copy of $K A T 6 B$ was found in a patient with a Noonan Syndrome-like phenotype of short stature, delayed bone age, dysmorphic features, cognitive anomalies, but no reported patellar problems [64]. As of yet there is no reported direct involvement of $K A T 6 B$ in DNA replication or cell division, although it is anticipated to play a role in epigenetic gene regulation.

Proteus syndrome ([MIM 176920]) involves severe and variable overgrowth of multiple tissues including bone, and is caused by somatic activating variants in the phosphoinositide 3-kinase, AKT1 ([MIM 164730], also known as PI3-kinase). AKT plays a key role in cell growth signaling pathways and some cancers, and patellar hyperplasia is a recurrent component of the phenotype [65].

Roberts syndrome (RBS, MIM[268300]) is a pleiotropic developmental disorder, the hallmarks of which include moderate to severe limb deficits, facial clefting, growth deficit but with genital enlargement, intellectual deficit, and variable internal organ defects [66]. Patellar hypoplasia is a variable component of the phenotype. RBS is considered allelic with the milder SC phocomelia. Cellular studies from patients noted abnormal mitotic chromosomes, suggestive of a problem with chromatin. RBS and SC phocomelia were subsequently shown to be caused by variants in the gene ESCO2 (MIM[609353]), an acetyltransferase involved in sister chromatid cohesion during mitosis [67].

Seckel syndrome [MIM 210600 for SCKL1 and a general description of the syndrome] represents a genetically heterogeneous group of related disorders, for which the basic phenotype includes dwarfism and microcephaly, together with a somewhat distinctive head with a narrow face, receding lower jaw, protruding nose, and large eyes causing a "bird-like" appearance. The genes known to mutate to cause Seckel include several components of centrosomes and other known players in DNA replication. There is phenotypic overlap between Seckel and microcephalic dwarfism especially type II [MIM 210720] [68] and MGORS, with Seckel cases typically showing disproportionately greater reduction in head size versus height compared to the other syndromes. One particular subtype of Seckel, SCKL1, caused by variants in the gene ATR, includes hypoplastic patellae in at least two published patients [69]. ATR [MIM 601215] encodes a kinase (Mecl in yeast) believed to play a role in DNA damage repair, and also in regulation of replication fork transit and origin firing as well possibly as other genomic functions [70].

\section{Disorders likely of bone development and/or differentiation}

(Table S1) The patella is expected to be affected in syndromes whose phenotypes include general defects in bone development and/or maintenance. There are no syndromes with identified genes specifically involved in bone physiology, where patellar involvement is the major phenotypic component. Instead, patellar involvement is variable, and sometimes atypical, in these syndromes. Even so, the genes shed some light on the requirements for patellar development (see Supplement for more details). Causal genes include two transcription factors known to participate in regulating bone growth and/or maturation: GDF5/CDMP1/ BMP14 (MIM[601146]) has patellar involvement in some cases of Du Pan syndrome (MIM[228900]); SOX9 (MIM [608160]) has a patellar phenotype in one reported case among many of campomelic dysplasia (MIM[114290]). Less obviously, a gene involved in muscle development and function has patellar involvement in some cases: the acetylcholine receptor subunit gamma gene CHRNG (MIM [100730]) in the Escobar variant of multiple pterygium syndrome (MIM[265000]). Possibly the patellar aspect of the Escobar type is secondary to reduced leg motion in utero, as studies of chemically paralyzed chick embryos support a requirement for muscle activity for proper patellar development [13]. Finally, in one subtype of Bruck syndrome (BRKS1 MIM[259450], Kuskokwim variant), which normally includes severe arthrygryposis (joint contractures) with attendant muscular atrophy, some cases include a patellar component. The causal gene, FKBP10 (MIM [607063]) which somewhat confusingly encodes protein FKBP65, appears to participate in proper collagen posttranslational processing.

\section{Other disorders}

Patellar involvement has been reported either in isolation or syndromic, in a number of cases for which a molecular cause remains to be found, or for which a genetic etiology is 
only hypothesized. See Supplemental Table S2 for more details on these phenotypes.

\section{Conclusions}

As discussed in this review, a wide range of genetic syndromes include patellar abnormalities as a component of the phenotype. In many cases, the causal genes are known to play roles in one of three processes: pattern formation, DNA replication/chromatin structure, or bone development/ differentiation.

One challenge in patellar genetics is the delayed normal ossification of the bone. Thus, syndromic cases ascertained younger than $\sim 5$ years of age cannot be reliably assessed for patellar development, as standard imaging cannot resolve defects in patellar cartilage. Moreover, essentially all the syndromes described in this review are ascertained in living probands, whereas patellar specification begins as early as 7 weeks of fetal development. In patellar hypoplasia/aplasia observed in children or adults, it is difficult to know how early the aberrant developmental process began. Published studies of knee joint ontogeny in genetically modified mice are similarly difficult to interpret as staining of embryos for bone does not visualize abnormal patellar cartilage development.

The involvement of housekeeping genes of DNA replication and/or repair, and chromatin structure, is one of the most unexpected aspects of patellar syndromes. There are several possible scenarios one can imagine for the role of these genes. Cells giving rise to the patellar anlage could have a special requirement for rapid division and genome replication. There is some precedent for such a model: cells in the developing brain have a special (though as yet not fully understood) requirement for a particular pattern of cell division, such that variants in many genes encoding ubiquitous components of the centrosomal machinery give rise to a relatively specific microcephaly phenotype. Alternatively, pathogenic variants in replication and chromatin genes may cause aberrant regulation of particular gene networks required for proper patellar specification or development. There is some evidence that origin recognition complexes play a role in gene regulation in yeast, in addition to their role in genome replication. Clearly studies in targeted mouse knock-in mutants carrying particular hypomorphic alleles of the identified causal genes would be helpful in understanding the basis of the patellar phenotype. CRISPR or related technologies make the construction of such targeted mutants eminently feasible.

Acknowledgements MES is supported by the Centre de Recherche du CHU Ste-Justine and Genome Canada. PMC is funded in part by clinician scientist awards from the Canadian Institutes of Health
Research (RN-315908) and the FRQS (30647). Thanks to Judith Hall, Leslie Biesecker, Jacques Michaud, and Grant Mitchell for helpful comments regarding particular genetic syndromes. Thanks to John Hutchinson and Sophie Regnault for helpful comments regarding patellar evolution. Thanks to the reviewers for helpful comments and suggestions for the manuscript. Illustrations were created by Manuela Bertoni.

\section{Compliance with ethical standards}

Conflict of interest The authors declare that they have no conflict of interest.

Publisher's note: Springer Nature remains neutral with regard to jurisdictional claims in published maps and institutional affiliations.

\section{References}

1. Vickaryous MK, Olson WM. Sesamoids and ossicles in the appendicular skeleton. In: Hall BK(ed). Fins into Limbs. Chicago: University of Chicago; 2007.

2. Samuels ME, Regnault S, Hutchinson JR. Evolution of the patellar sesamoid bone in mammals. PeerJ. 2017;5:e3103.

3. Gardner E, O'Rahilly R. The early development of the knee joint in staged human embryos. J Anat. 1968;102:289-99.

4. Fox AJ, Wanivenhaus F, Rodeo SA. The basic science of the patella: structure, composition, and function. J knee Surg. 2012;25:127-41.

5. Merida-Velasco JA, Sanchez-Montesinos I, Espin-Ferra J, Rodriguez-Vazquez JF, Merida-Velasco JR, Jimenez-Collado J. Development of the human knee joint. Anat Rec. 1997;248: 269-78.

6. Haines RW. The tetrapod knee joint. J Anat. 1942;76:270-301.

7. Herzmark MH. Evolution of the knee joint. J Bone Joint Surg. 1938;200:77-84.

8. Smith HF, Parker W, Kotze SH, Laurin M. Multiple independent appearances of the cecal appendix in mammalian evolution and an investigation of related ecological and anatomical factors. Comptes Rendus Palevol. 2013;12:339-54.

9. Bongers EM, van Kampen A, van Bokhoven H, Knoers NV. Human syndromes with congenital patellar anomalies and the underlying gene defects. Clin Genet. 2005;68:302-19.

10. Vanlerberghe C, Boutry N, Petit F. Genetics of patella hypoplasia/ agenesis. Clin Genet. 2018;94:43-53.

11. Warman ML, Cormier-Daire V, Hall C, et al. Nosology and classification of genetic skeletal disorders: 2010 revision. Am J Med Genet Part A. 2011;155A:943-68.

12. Rot-Nikcevic I, Reddy T, Downing KJ, et al. Myf5-/-:MyoD-/amyogenic fetuses reveal the importance of early contraction and static loading by striated muscle in mouse skeletogenesis. Dev Genes Evol. 2006;216:1-9.

13. Hosseini A, Hogg DA. The effects of paralysis on skeletal development in the chick embryo. I. General effects. J Anat. 1991;177:159-68.

14. Bongers EM, Huysmans FT, Levtchenko E, et al. Genotypephenotype studies in nail-patella syndrome show that LMX1B mutation location is involved in the risk of developing nephropathy. Eur J Hum Genet. 2005;13:935-46.

15. Sweeney E, Fryer A, Mountford R, Green A, McIntosh I. Nail patella syndrome: a review of the phenotype aided by developmental biology. J Med Genet. 2003;40:153-62.

16. Knoers NV, Bongers EM, van Beersum SE, Lommen EJ, van Bokhoven H, Hol FA. Nail-patella syndrome: identification of 
mutations in the LMX1B gene in Dutch families. J Am Soc Nephrol. 2000;11:1762-6.

17. Salcedo JR. An autosomal recessive disorder with glomerular basement membrane abnormalities similar to those seen in the nail patella syndrome: report of a kindred. Am $\mathrm{J}$ Med Genet. 1984;19:579-84.

18. Scott JE, Taor WS. The "small patella" syndrome. J Bone Jnoit Surg. 1979;61-B:172-5.

19. Azouz EM, Kozlowski K. Small patella syndrome: a bone dysplasia to recognize and differentiate from the nail-patella syndrome. Pediatr Radiol. 1997;27:432-5.

20. Bongers EM, Duijf PH, van Beersum SE, et al. Mutations in the human TBX4 gene cause small patella syndrome. Am J Hum Genet. 2004;74:1239-48.

21. Gibson-Brown JJ, Agulnik SI, Chapman DL, et al. Evidence of a role for T-box genes in the evolution of limb morphogenesis and the specification of forelimb/hindlimb identity. Mech Dev. 1996;56:93-101.

22. Isaac A, Rodriguez-Esteban $\mathrm{C}$, Ryan $\mathrm{A}$, et al. Tbx genes and limb identity in chick embryo development. Development. 1998;125:1867-75.

23. Naiche LA, Papaioannou VE. Loss of Tbx4 blocks hindlimb development and affects vascularization and fusion of the allantois. Development. 2003;130:2681-93.

24. Minguillon C, Del Buono J, Logan MP. Tbx5 and Tbx4 are not sufficient to determine limb-specific morphologies but have common roles in initiating limb outgrowth. Dev Cell. 2005;8:7584.

25. Gurnett CA, Alaee F, Kruse LM, et al. Asymmetric lower-limb malformations in individuals with homeobox PITX1 gene mutation. Am J Hum Genet. 2008;83:616-22.

26. Spielmann M, Brancati F, Krawitz PM, et al. Homeotic arm-to-leg transformation associated with genomic rearrangements at the PITX1 locus. Am J Hum Genet. 2012;91:629-35.

27. Szeto DP, Rodriguez-Esteban C, Ryan AK, et al. Role of the Bicoid-related homeodomain factor Pitx1 in specifying hindlimb morphogenesis and pituitary development. Genes Dev. 1999;13:484-94.

28. Lanctot C, Moreau A, Chamberland M, Tremblay ML, Drouin J. Hindlimb patterning and mandible development require the Ptx 1 gene. Development. 1999;126:1805-10.

29. DeLaurier A, Schweitzer R, Logan M. Pitx1 determines the morphology of muscle, tendon, and bones of the hindlimb. Dev Biol. 2006;299:22-34.

30. Logan M, Tabin CJ. Role of Pitx1 upstream of Tbx4 in specification of hindlimb identity. Science. 1999;283:1736-9.

31. Woods CG, Stricker S, Seemann P, et al. Mutations in WNT7A cause a range of limb malformations, including Fuhrmann syndrome and Al-Awadi/Raas-Rothschild/Schinzel phocomelia syndrome. Am J Hum Genet. 2006;79:402-8.

32. Fuhrmann W, Fuhrmann-Rieger A, de Sousa F. Poly-, syn- and oligodactylyl, aplasia or hypoplasia of fibula, hypoplasia of pelvis and bowing of femora in three sibs--a new autosomal recessive syndrome. Eur J Pediatr. 1980;133:123-9.

33. Altabef M, Tickle C. Initiation of dorso-ventral axis during chick limb development. Mech Dev. 2002;116:19-27.

34. Yang Y, Niswander L. Interaction between the signaling molecules WNT7a and SHH during vertebrate limb development: dorsal signals regulate anteroposterior patterning. Cell. 1995;80:939-47.

35. Kjaer KW, Hansen L, Eiberg H, Christensen KS, Opitz JM, Tommerup N. Male-to-male transmission in Laurin-Sandrow syndrome and exclusion of RARB and RARG. Am J Med Genet Part A. 2005;137:148-52.

36. Lohan S, Spielmann M, Doelken SC, et al. Microduplications encompassing the Sonic hedgehog limb enhancer ZRS are associated with Haas-type polysyndactyly and Laurin-Sandrow syndrome. Clin Genet. 2014;86:318-25.

37. Ianakiev P, van Baren MJ, Daly MJ, et al. Acheiropodia is caused by a genomic deletion in C7orf2, the human orthologue of the Lmbr1 gene. Am J Hum Genet. 2001;68:38-45.

38. Dolezal D, Liu Z, Zhou Q, Pignoni F. Fly LMBR1/LIMR-type protein Lilipod promotes germ-line stem cell self-renewal by enhancing BMP signaling. Proc Natl Acad Sci USA. 2015;112:13928-33.

39. Smith JD, Hing AV, Clarke CM, et al. Exome sequencing identifies a recurrent de novo ZSWIM6 mutation associated with acromelic frontonasal dysostosis. Am J Hum Genet. 2014;95: 235-40.

40. Zakany J, Duboule D. The role of Hox genes during vertebrate limb development. Curr Opin Genet Dev. 2007;17:359-66.

41. Koyama E, Yasuda T, Minugh-Purvis N, et al. Hox11 genes establish synovial joint organization and phylogenetic characteristics in developing mouse zeugopod skeletal elements. Development. 2010;137:3795-800.

42. Carpenter EM, Goddard JM, Davis AP, Nguyen TP, Capecchi MR. Targeted disruption of Hoxd-10 affects mouse hindlimb development. Development. 1997;124:4505-14.

43. Wahba GM, Hostikka SL, Carpenter EM. The paralogous Hox genes Hoxa10 and Hoxd10 interact to pattern the mouse hindlimb peripheral nervous system and skeleton. Dev Biol. 2001;231:87102.

44. Dobbs MB, Gurnett CA, Pierce B, et al. HOXD10 M319K mutation in a family with isolated congenital vertical talus. J Orthop Res. 2006;24:448-53.

45. Thompson AA, Nguyen LT. Amegakaryocytic thrombocytopenia and radio-ulnar synostosis are associated with HOXA11 mutation. Nat Genet. 2000;26:397-8.

46. Bongers EM, Opitz JM, Fryer A, et al. Meier-Gorlin syndrome: report of eight additional cases and review. Am J Med Genet. 2001;102:115-24.

47. Guernsey DL, Matsuoka M, Jiang H, et al. Mutations in origin recognition complex gene ORC4 cause Meier-Gorlin syndrome. Nat Genet. 2010;43:360-4.

48. Bicknell LS, Walker S, Klingseisen A, et al. Mutations in ORC1, encoding the largest subunit of the origin recognition complex, cause microcephalic primordial dwarfism resembling MeierGorlin syndrome. Nat Genet. 2010;43:350-5.

49. Bicknell LS, Bongers EM, Leitch A, et al. Mutations in the prereplication complex cause Meier-Gorlin syndrome. Nat Genet. 2010;43:356-9.

50. Burrage LC, Charng WL, Eldomery MK, et al. De novo GMNN mutations cause autosomal-dominant primordial dwarfism Associated with Meier-Gorlin syndrome. Am J Hum. Genet. 2015;97:904-13.

51. Fenwick AL, Kliszczak M, Cooper F, et al. Mutations in CDC45, encoding an essential component of the pre-initiation complex, cause Meier-Gorlin syndrome and craniosynostosis. Am J Hum. Genet. 2016;99:125-38.

52. Vetro A, Savasta S, Russo Raucci A et al. MCM5: a new actor in the link between DNA replication and Meier-Gorlin syndrome. Eur J Hum Genet. 2017;25:646-50.

53. Kang S, Kang MS, Ryu E, Myung K. Eukaryotic DNA replication: orchestrated action of multi-subunit protein complexes. Mutat Res. 2018;809:58-69.

54. Parker MW, Botchan MR, Berger JM. Mechanisms and regulation of DNA replication initiation in eukaryotes. Crit Rev Biochem Mol Biol. 2017;52:107-44.

55. Klingseisen A, Jackson AP. Mechanisms and pathways of growth failure in primordial dwarfism. Genes Dev. 2011;25: 2011-24. 
56. Kaariainen H, Ryoppy S, Norio R. RAPADILINO syndrome with radial and patellar aplasia/hypoplasia as main manifestations. Am J Med Genet. 1989;33:346-51.

57. Siitonen HA, Kopra O, Kaariainen H, et al. Molecular defect of RAPADILINO syndrome expands the phenotype spectrum of RECQL diseases. Hum Mol Genet. 2003;12:2837-44.

58. Larizza L, Magnani I, Roversi G. Rothmund-Thomson syndrome and RECQL4 defect: splitting and lumping. Cancer Lett. 2006;232:107-20.

59. Sangrithi MN, Bernal JA, Madine $M$, et al. Initiation of DNA replication requires the RECQL4 protein mutated in RothmundThomson syndrome. Cell. 2005;121:887-98.

60. Cormier-Daire V, Chauvet ML, Lyonnet S, Briard ML, Munnich A, Le Merrer M. Genitopatellar syndrome: a new condition comprising absent patellae, scrotal hypoplasia, renal anomalies, facial dysmorphism, and mental retardation. J Med Genet. 2000;37:520-4.

61. Reardon W. Genitopatellar syndrome: a recognizable phenotype. Am J Med Genet. 2002;111:313-5.

62. Simpson MA, Deshpande C, Dafou D, et al. De novo mutations of the gene encoding the histone acetyltransferase KAT6B cause Genitopatellar syndrome. Am J Hum Genet. 2012;90:290-4.

63. Campeau PM, Kim JC, Lu JT, et al. Mutations in KAT6B, encoding a histone acetyltransferase, cause Genitopatellar syndrome. Am J Hum Genet. 2012;90:282-9.
64. Kraft M, Cirstea IC, Voss AK, et al. Disruption of the histone acetyltransferase MYST4 leads to a Noonan syndrome-like phenotype and hyperactivated MAPK signaling in humans and mice. J Clin Invest. 2011;121:3479-91.

65. Biesecker LG. The multifaceted challenges of Proteus syndrome. JAMA. 2001;285:2240-43.

66. Freeman MV, Williams DW, Schimke RN, Temtamy SA, Vachier E, German J. The Roberts syndrome. Clin Genet. 1974;5: $1-6$.

67. Vega H, Waisfisz Q, Gordillo $\mathrm{M}$, et al. Roberts syndrome is caused by mutations in ESCO2, a human homolog of yeast ECO1 that is essential for the establishment of sister chromatid cohesion. Nat Genet. 2005;37:468-70.

68. Willems M, Genevieve D, Borck G, et al. Molecular analysis of pericentrin gene (PCNT) in a series of $24 \mathrm{Seckel} / \mathrm{microcephalic}$ osteodysplastic primordial dwarfism type II (MOPD II) families. J Med Genet. 2010;47:797-802.

69. Ogi T, Walker S, Stiff T, et al. Identification of the first ATRIPdeficient patient and novel mutations in ATR define a clinical spectrum for ATR-ATRIP seckel syndrome. PLoS Genet. 2012;8: e1002945.

70. Lanz MC, Oberly S, Sanford EJ, Sharma S, Chabes A, Smolka MB. Separable roles for Mec1/ATR in genome maintenance, DNA replication, and checkpoint signaling. Genes Dev. 2018;32:822-35. 